\title{
Demystifying computational thinking for teacher candidates: A case study on Turkish secondary school pre-service teachers
}

\author{
Armağan Ateşkan ${ }^{1}$ D $\cdot$ Deniz Ortactepe Hart ${ }^{2}$
}

Received: 8 March 2021 / Accepted: 7 June 2021 / Published online: 22 June 2021

(c) The Author(s), under exclusive licence to Springer Science+Business Media, LLC, part of Springer Nature 2021

\begin{abstract}
The present study is based on a teaching-module designed to introduce computational thinking (CT) to pre-service teachers pursuing MA degrees at a large-scale university in Ankara, Turkey. It aims to explore Turkish pre-service teachers' perceptions and integration of CT in different disciplines through CT-based tasks. Preand post-attitude questionnaires were administered before and after the presentation of a CT module to find out about their self-efficacy of computer use in class, perceptions of computing and CT, and integration of CT into their classrooms and in other disciplines. Student lesson plans were analysed in order to explore the challenges they faced while integrating CT into their teaching. According to the results, the pre-service teachers in this study 1) gained an awareness that computing, and CT are more than using computers and technology but relate to the process of problemsolving, 2) developed a better understanding of how to integrate CT into their teaching, and 3) agreed that CT could and should be integrated into the teaching of other disciplines, and 4) integrated different CT vocabulary in lesson plans based on their specific subject area.
\end{abstract}

Keywords Computational thinking $\cdot$ Pre-service teacher education $\cdot$ Problemsolving skills · WebQuest

Armağan Ateşkan

ateskan@bilkent.edu.tr

Deniz Ortactepe Hart

dortactepe@miis.edu

1 Bilkent University Faculty of Education, Bilkent, 06800 Ankara, Turkey

2 Middlebury Institute of International Studies at Monterey, Monterey, CA, USA 


\section{Introduction}

With the improvements in educational technology, computational thinking (CT) has become one of the fundamental skills of the twenty-first century both teachers and students are expected to develop. According to Wing (2006), CT refers to the process of "solving problems, designing systems, and understanding human behaviour by drawing on the concepts fundamental to computer science" (p. 33). With its emphasis on the role of computers in teaching and learning processes, CT is not a skill for only computer scientists but for everyone involved in analytical thinking for reading, writing, and arithmetic purposes (Selby, 2015). According to Hemmendinger (2010), the goal of computational thinking in other disciplines should be "to teach them [learners] how to think like an economist, a physicist, an artist, and to understand how to use computation to solve their problems, to create, and to discover new questions that can fruitfully be explored" (p. 6). The present paper, thus, presents a case study on Turkish pre-service teachers who pursued MA degrees in teaching science, mathematics, English and Turkish language and their experiences of a CT module that aimed to develop their awareness and integration of CT in their own classes.

\subsection{Computational thinking (CT)}

According to Wing (2006), computational thinking (CT) indicates a "thought process involved in formulating problems and their solutions so that the solutions are represented in a form that can be effectively carried out by an information-processing agent" (p. 1). CT embodies a wide range of analytic and problem-solving skills, habits, approaches, and perspectives that help learners solve problems in all disciplines (Barr \& Stephenson, 2011; Bers et al., 2014; Grover \& Pea, 2013; Lye \& Koh, 2014; Yadav et al., 2016; Yadav et al., 2017; Yeh et al., 2011). Abstraction (e.g., problem representation) and decomposition (e.g., reformulating a problem) lie at the centre of computational thinking as these two analytical processes help accomplish complex tasks and/or discover a solution (Wing, 2006). With its problem-solving orientation (Barr et al., 2011; Yadav et al., 2016), CT helps learners develop new perspectives and seek alternative solutions that are "usually outside a student's normal area of expertise, or schemata" (Ioannidou et al., 2011, p. 4).

\subsection{The need for computational thinking in pre-service education}

Several scholars have argued that CT should be introduced to students in K-12 rather than in colleges as many of today's learners will need computing in their lives (Barr \& Stephenson, 2011; Grover \& Pea, 2013; Sengupta et al., 2013; Yadav et al., 2016). Studies have suggested certain benefits of integrating computational thinking into mathematics and science education (Hambrusch et al., 2009; Sengupta et al., 2013) as computational thinking through modelling could enhance the learning of 
relatively more difficult science and math concepts (Blikstein \& Wilensky, 2009) and mathematical reasoning (Wing, 2008). In their study, Hambrusch et al. (2009) designed a CT course for science majors based on the following principles:

- lay the groundwork for computational thinking

- present examples in a language familiar to the students

- teach in a problem-driven way

- the programming language should right away allow a focus on computational principles

- make effective use of visualisation. (p. 184)

According to their results, the problem-solving approach they adopted based on these principles led to an increase in science major students' interest in computing implying that all science disciplines including biology and physics can benefit from an introductory course on computational thinking.

Expanding the scope of CT to other disciplines, several researchers have agreed that CT encourages multiple levels of abstraction, decomposition, verification, and prediction that people use to solve daily problems, manage their lives, and interact with others (Bundy, 2007; Kramer, 2007; Sengupta et al., 2013; Wing, 2006). In other words, when applied to other disciplines, CT can promote learner creativity that will be put into use in order to explore unique and innovative solutions to complex problems that are encountered in their disciplines (Ioannidou et al., 2011; Mishra et al., 2013). While Barr and Stephenson (2011) explain the importance of $\mathrm{CT}$ in fostering creativity as "students become not merely tool users but tool builders" (p. 51), according to Mishra et al. (2013), CT allows them "not only be consumers of technology, but also build tools that can have significant impact on society" (p. 11).

In order to raise pre-service teachers' awareness of integrating CT in their classes, Yadav and his colleagues (Yadav et al., 2011) designed a CT module and examined its influence on pre-service teachers' attitudes toward CT through a pre- and posttest design. The results indicated an increase in students' perceptions of CT as a skill that relates to all fields and that can be integrated into other disciplines and/in various content-area courses such as teaching methods. Their study, however, only used an attitude questionnaire to explore pre-service teachers' understanding and integration of CT. Therefore, the present study aims to explore pre-service teachers' CT perceptions as well as integration of CT in different disciplines through a WebQuest task that relied on $\mathrm{CT}$ principles.

While doing so, this study answers Barr and Stephenson's (2011) call for bringing computational thinking to K-12 by including a CT module into a pre-service education program. According to these researchers, integrating CT into K-12 requires pondering upon four critical questions: "What would computational thinking look like in the classroom? What are the skills that students would demonstrate? What would a teacher need in order to put computational thinking into practice? What are teachers already doing that could be modified and extended?" (p. 50). Thus, this study, by implementing a CT module designed for secondary school pre-service teachers in various disciplines, aimed to find out their attitudes towards computing 
and CT as well as the ways they integrated CT into the classrooms and other disciplines. Research questions of this study were as follows:

a) What are secondary school pre-service teachers' attitudes towards computing and CT?

b) In what ways do they promote the use of CT skills and vocabulary in their classes?

\section{Research design}

This case study (Yin, 2003) aimed to explore the impact of a module that was designed to raise pre-service teachers' awareness of CT. The CT module had two main purposes: first to introduce the $\mathrm{CT}$ terminology to the pre-service teachers in order to raise their awareness of $\mathrm{CT}$, and second, to promote their integration of $\mathrm{CT}$ in their future teaching experiences by discussing the relevant principles and practices.

\subsection{Overview of the CT module}

A three-week (12 h in total) CT module was developed for the secondary school pre-service teachers as part of the "Instructional Technology and Materials Development" course. In this course, secondary school pre-service teachers learned about teaching with technology (using MS Office programs), graphic organizers, WebQuest, interactive white board, smart mobile device applications, digital storytelling, and e-portfolio. The CT module was embedded into this course as it included problem solving, systems design, and understanding human behaviour, which fit very well into course objectives (e.g., design activities to support problem solving, data collection, information management, and decision making). The module aimed to foster pre-service teachers' computational thinking skills such as representing a problem (abstraction), representing data through abstraction (simulation), a step-bystep process of problem-solving on multiple levels (algorithm), collecting data and implementing possible solutions as well as by trouble shooting potential difficulties (debugging).

The course materials that were used as part of this module were adopted from Purdue University and Computer Science Teachers Association with permission. Before the CT module, a pre-attitude questionnaire about computing and computational thinking was administered to the teacher candidates. Although the administration of a pre-test calls for pre-test sensitization bias (Lam \& Bengo, 2003), the items in the questionnaire were not designed in a way to make students become aware of what CT is or to scaffold ideas related to the integration of CT.

During the CT lectures, the pre-service teachers answered sets of daily life questions such as how to go to a designated address and how to find out solutions to a given problem (e.g., a desk lamp that is not working and serving pizza to 60 people in one room). With the help of these tasks, the terms abstraction, 
decomposition, logical thinking, algorithms, and debugging were implicitly introduced to the pre-service teachers without explicitly mentioning their names.

In addition to the course lectures and discussions, a WebQuest task was assigned to the pre-service teachers in order to introduce them to the concept of $\mathrm{CT}$, to provide opportunities for them to understand it, and to encourage them to apply CT in their own discipline and instructional practice (Fig. 1 presents the screenshot of the WebQuest task).

For completing this task, the course instructor - the first author of this study -provided web-based resources through which pre-service teachers could explore what CT is and see sample CT activities integrated into different disciplines. At the end of their study, pre-service teachers posted their WebQuest products (including their lesson plans) to an online discussion forum on Moodle, which was the course learning management system. They provided feedback to each other through peer-review sessions, which was then followed by instructor's feedback. During the last week of the CT module, there were both in person wholeclass discussions and online discussions on Moodle on their WebQuest products. These discussions helped summarize the basic principles of CT and models for integrating CT into their lessons. At the end of the module, a post-attitude questionnaire was administered to the participating pre-service teachers. The summary of the three-week module is presented in Fig. 2.

\section{Tasks}

Imagine that you have just been hired for your first teaching position. The principal of your school asks for your help in addressing a new state standard on computational thinking. The principal explains, "There is a new academic standard which states that students should have an understanding of computational thinking and its application in design and problem solving in real-world contexts. As I understand it, computational thinking is something that can be addressed no matter which subject is being taught. The expectation is that students will be able to see that computational thinking is everywhere in daily life and can be applied to a wide variety of problems and content." The principal continues, "I know you had course work in educational technology at university, so I think you can set an example for the rest of the faculty by developing an activity for your classroom to introduce your students to computational thinking."

\section{So, your task is to design a class activity to introduce your students to some} aspect of computational thinking and/or its application.

To complete your task, follow the steps outlined in Process.

Fig. 1 The screenshot of the WebQuest assigned to the pre-service teachers 


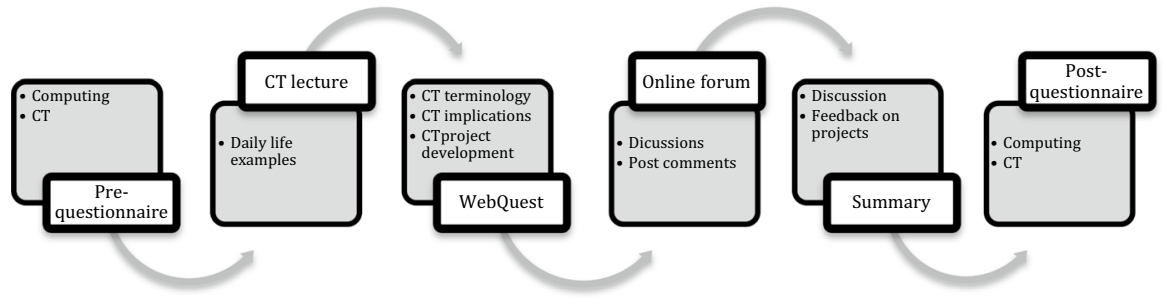

Fig. 2 CT module for pre-service teachers

\subsection{Participants, instruments, and data collection}

The participants of this study were 45 teacher candidates pursuing an MA degree in Curriculum and Instruction with Teaching Certificate at a non-profit foundation university in Ankara, Turkey. The aim of this MA program was to prepare qualified teachers for leadership who would serve the Turkish education system. As part of this two-year master's program, the students also received the certificate of International Baccalaureate Diploma Programme in Teaching and Learning and were trained to be teaching at secondary schools in various disciplines. The participants of the study were in their first year of the program and enrolled in the 'TE 520 Instructional Technology and Materials Development' course. There were 11 biology, 14 mathematics, 13 English Language and Literature and 7 Turkish Language and Literature pre-service teachers. Their ages ranged from 20 to 23.

The instrument used to collect data for the first research question was an on-line pre- and post-attitude questionnaire adapted from Yadav et al. (2011). The questionnaire consisted of two sections; 16-item four-point Likert scale ranged from 1(strongly disagree) to 4 (strongly agree) and four open-ended questions. The first section included questions that are related to self-efficacy of computer use in class (4 items), knowledge of computer (4 items), job satisfaction (4 items), problem solving with the use of computer (2 items), and integration of computational thinking into classroom (2 items). In the second section, there were four open ended questions that investigated participants' perceptions on computing, CT, integration of CT into classroom, and CT's relevance to other disciplines. The pre-attitude questionnaire was completed by 45 pre-service teachers while the post-attitude questionnaire was completed by 41 students as four students were not present in the class the day the questionnaire was administered. Cronbach alpha for the pre- and post-attitude questionnaires are .814 and .776 , respectively, indicating an acceptable level of internal consistency (Nunnally, 1978).

The other data collection source for this study was participants' WebQuest products and their online discussion posts. As mentioned earlier, the participants completed a WebQuest as part of their course requirement. This scenario-based task asked them to assume that they were a novice teacher and a change agent for a new national standard related to $\mathrm{CT}$ and its application in design and problem solving in real-world contexts (see Fig. 1 above). Based on the task that they designed, students would be able to see that computational thinking is everywhere in their daily lives 
and can be applied to a wide variety of contexts. As part of their WebQuest task, the participants were also required to post their lesson plans to an online discussion forum on Moodle. They also had to review two of their friends' lesson plan and comment on it. Thus, their WebQuest product and online discussion posts were also examined as data sources in this study to see how they integrated CT into their own disciplines as well as their attitudes towards CT. All data were collected in English since the medium of instruction at the institution where the study was conducted is English. Thus, the pre-service teachers' comments as well as the samples of their WebQuest products are presented in their own words without any changes/translation. The ethical approval was gathered from the Institutional Review Board of the university and the participants signed informed consent forms.

\subsection{Data analysis}

Data were analysed both quantitatively and qualitatively. Descriptive statistics, including means and standard deviations, were calculated for 16 Likert scale questions. Paired samples $t$-test was used with the Statistical Package for Social Science (SPSS) software for comparison of pre-service teachers' responses to the questions before and after the module.

The common analytic approach was used for analysing the four open ended questions that formed the qualitative data (Miles \& Huberman, 1994). First, some recurrent codes were generated inductively (Corbin \& Strauss, 2008). Afterwards, these codes were categorized to have a general idea of the emerging themes. After this first-level coding, all categories from each document were grouped under major themes, that were then grouped into more comprehensive themes. The four openended questions were coded, and categories were developed based on the literature review (Yadav et al., 2011). To analyse the WebQuest products (lesson plans), the International Society for Technology in Education (ISTE)'s framework for CT vocabulary (CTV) and progression chart was used (International Society for Technology Education (ISTE, 2011). Key vocabulary that is used in the CT framework include data collection, data analysis, data representation, problem decomposition, abstraction, algorithms and procedures, automation, simulation, parallelization. A content analysis was carried out, as a result of which frequencies of CTV are revealed in order to see how the participants promoted CT skills in their lesson plans.

\section{Results}

\subsection{Pre-service teachers' attitudes towards computing and CT}

The total mean scores of the 16 Likert scale questions in the pre- and post-attitude questionnaires were compared with the paired samples $t$-test. The results revealed a statistically significant difference between the pre-test mean scores of the pre-service students $(M=3.18, S D=.43)$ and their post-test mean scores $(M=3.36, S D=.31)$ : 
$95 \% \mathrm{CI}[-0.34,0.03], t(40)=-2.426, p<.05, d=0.48$. That is, the attitudes of the pre-service teachers towards CT changed significantly after the presentation of the CT module (See Table 1).

In order to understand the details of this attitudinal change, and as a follow up analysis of the general comparison of the means of the total attitude scores, each item in the pre- and post-attitude questionnaire was compared again with the paired samples $t$-test. According to the results, there were four items that showed a statistically significant difference (Item \# 3, 4, 14, 15, see Table 1). For the rest of the items the results were not statistically significant.

First, the pre-service teachers' attitudes showed a statistically significant difference for the third item of the attitude questionnaire (i.e., I doubt that I can solve problems by using computer applications) (Pre-test $M=2.17, S D=.86$; Post-test $M=3.53, S D=.63): 95 \%$ CI $[-1.74,-.098], t(40)=-7.294, p<.05, d=1.8$. Second, the fourth item on the questionnaire (i.e., The challenge of solving problems using computer science appeals to me) also indicated a statistically significant difference across pre- and post-attitude questionnaire (Pre-test $M=3.09 S D=.96 ; M=3.60$, $S D=.69) ; 95 \% \mathrm{CI}[0.13,0.88], t(40)=-2.766, p<.05, d=0.6)$. These two results indicate that the pre-service teachers, after the presentation of the CT module, have come to realize the role of computer applications for problem solving.

The other two items that showed statistically significant differences between the pre- and post-attitude questionnaires were related to the integration of computational thinking into classrooms in other disciplines. The pre-service teachers' attitude scores for the 14th item of the attitude questionnaire (i.e., Computational thinking can be integrated into classroom education in other fields) increased after the CT module (Pre-test $M=2.95, S D=1.04$; Post-test $M=3.56, S D=.63,95 \%$ $\mathrm{CI}[-1.02,-0.19], t(40)=-3.00, p<.05, d=0.7$. In a similar vein, the pre-service teachers' attitudes towards the integration of CT into other disciplines also became more positive at the end of the study as indicated by the 15 th item (i.e., Computational thinking should be integrated into classroom education for other disciplines) (Pre-test $M=3.00, S D=1.00$; Post-test $M=3.46, S D=.67,95 \%$ CI[0.83, 0.08], $t(40)=-2.503, p<.05, d=0.5$. Other than these four items, no significant difference

Table 1 The comparison of the pre- and post-attitude questionnaire

\begin{tabular}{llllll}
\hline & Attitude Survey & $\mathrm{N}$ & $M$ & $\mathrm{SD}$ & $t$ \\
\hline \multirow{2}{*}{ Total score } & Pre- & 45 & 3.18 & .43 & $-2.426^{*}$ \\
& Post- & 41 & 3.36 & .31 & \\
\multirow{2}{*}{ Item 3 } & Pre- & 45 & 2.17 & .86 & $-7.294^{*}$ \\
& Post- & 41 & 3.53 & .63 & \\
\multirow{2}{*}{ Item 4 } & Pre- & 45 & 3.09 & .96 & $-2.766^{*}$ \\
& Post- & 41 & 3.60 & .69 & \\
Item 14 & Pre- & 45 & 2.95 & 1.04 & $-3.000^{*}$ \\
& Post- & 41 & 3.56 & .63 & \\
Item 15 & Pre- & 45 & 3.00 & 1.00 & $-2.503^{*}$ \\
& Post- & 41 & 3.46 & .67 & \\
\hline
\end{tabular}

$* p<.05$ 
was observed in items related to self-efficacy of computer use in class, knowledge of computer, job satisfaction, and their interest level of computer science. These nonstatistically significant findings can be explained by students' previous experiences taking an educational technology course and the role computers play in today's students' academic and social lives.

\subsection{Qualitative results regarding participants' perceptions of computing and CT}

\subsubsection{Pre-service teachers' view of computing}

In the first open-ended question, the participants were asked to define computing and its purpose. Their responses for the pre- and post-attitude questionnaires were analysed according to their percentages for the following three themes (see Fig. 3):

As seen in Fig. 3, the participants' attitudes toward computing shifted from computing for the use of computers and solving problems to the process of solving a problem by using computers. More specifically, the majority of the pre-service teachers in the pre-attitude questionnaire (68\%) made statements that deemed computing as using computers and/or technology to solve a problem and make tasks easier. For instance, in the pre-attitude questionnaire, pre-service teacher (PT) 1 stated,
A: To use computers and/or technology to solve a problem
B: The process of solving problems (without using computers)
$\mathrm{C}$ : The study of computer science

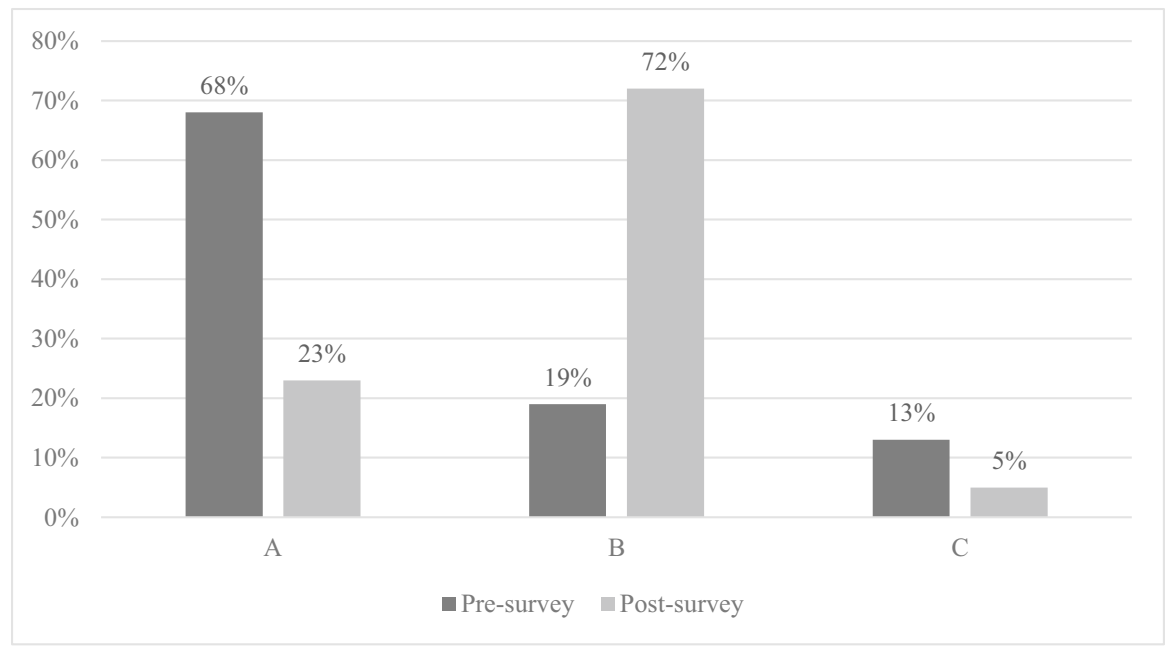

Fig. 3 Participants' view of computing according to the pre- and post-attitude questionnaire 
"Computing means to me to do almost all kinds of work that one could do in daily life through a machine, which makes such work easier and faster to be done." PT 2 also defined computing as, “...computer's available resources to make life easier. Especially as a future teacher, it enables me to give my resources outside of the classroom. Also facilitates to make some concepts concrete."

In the pre-attitude questionnaire, only $19 \%$ of the pre-service teachers referred to computing as the process of solving problems as PT 3 stated "For me computing is a way to use our minds in different ways. It requires thinking the process for solving a problem". Similarly, $13 \%$ of the pre-service teachers defined computing as the study of computer science. PT 4 stated, "Computing is the ability to use the programs and applications of the computers." Another pre-service teacher said, "I think computing is to have knowledge about usage of computer or some computer coding programs." These comments show that pre-service teachers accepted computing as the use of computers for problem solving, rather than the process of problem solving itself.

On the other hand, the post-test results showed that $72 \%$ of the pre-service teachers had statements that considered computing as the process of solving problems. PT 5 said, "I think that computing can be related to analytical thinking for problem solving process." Similarly, PT 6 stated, "In my opinion computing means to find the solution of the problems." PT 7 also said, "Computing is using computer and its applications to solve problems. It makes problem solving process faster." There was only one participant, however, who indicated that computing is for computer scientists. These findings show that pre-service teachers' view of computing changed from the use of computers for problem solving to the process of problem solving even without the use of computers.

\subsubsection{Pre-service teachers' view of CT}

In the second open-ended question, the participants were asked to define CT from their own perspectives. Figure 4 below presents their responses for pre- and postattitude questionnaires in terms of four themes.

As seen in Fig. 4, the participants' attitudes toward CT moved from using computers and/or technology to solving a problem to the process of solving problems even without using computers. In particular, according to pre-attitude questionnaire results, $35 \%$ of the participants were not familiar with CT as they had not heard the term before, yet, presumed that CT is the process of solving problems. PT 8 stated, "Computational thinking is quick thinking with algorithms." There were 48\% of the students who thought that CT is "to use computers and/or technology to solve a problem." For instance, PT 9 stated, "It is the application of computer or similar technology in our tasks and also getting advice from computer." According to 9\% of the participants, CT is the study of computer science. PT 10 stated, "It is to understand the logic behind how computer programs work." On the other hand, $8 \%$ the participants did not make comments in terms of what CT refers to.

After the presentation of the CT module, based on the results of the post-attitude questionnaire, the majority (77\%) of the participants' responses reflected that CT is "the process of solving problems." According to PT 11, "CT helps to give view of problem solving. We can use computers or not." On the other hand, 23\% of 

A: The process of solving problems (without using computers)
B: To use computers and/or technology to solve a problem
C: The study of computer science
D: Not sure

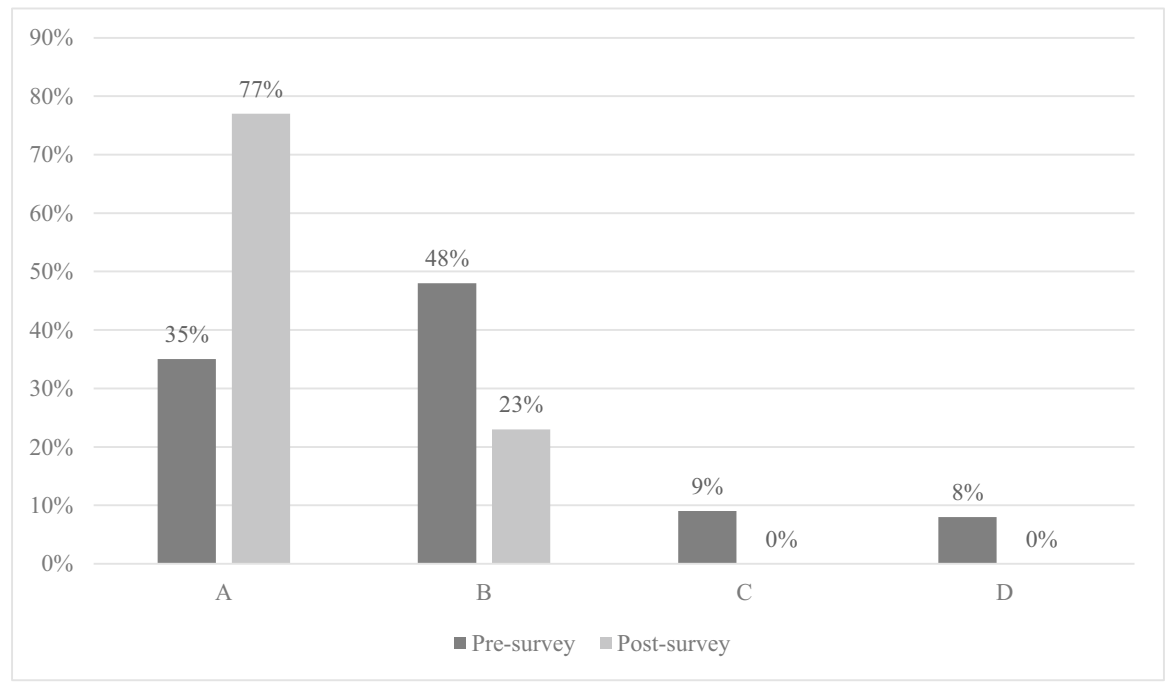

Fig. 4 Participants' view of CT according to the pre- and post-attitude questionnaire

them viewed CT as "to use computers and/or technology to solve a problem." PT 12 wrote, "In CT, we use computer programs to solve daily life problems and create more beneficial solutions while consuming time." These findings confirm the results of the previous section in the sense that after the CT module, the pre-service teachers' definition of CT shifted from the skill of using computers and/or technology to solve a problem to the skill of problems solving itself.

\subsection{Integration of $\mathrm{CT}$ into other disciplines}

In order to answer the second research question, the last two open-ended questions of the pre- and post-test and WebQuest products (including their lesson plans) were analysed. As for the first question, before the CT module, the participants stated that CT is related to science and mathematics mainly. Whereas after the module, besides science and mathematics, participants included history, geography, literature and $75 \%$ of them stated all disciplines are related to CT. PT 13 stated that, "In, English we can use games in our lessons and students may use CT to apply algorithms to the possible outcomes of the board games. While they are prepared to play games, they can guess the possible alternatives at the end of the game." 
In their responses to the second question, the participants explained how they would integrate CT into their classroom. See Fig. 5 for their responses for preand post-attitude questionnaire in terms of promoting problem solving skills in the classroom, utilizing computers and technology in the classroom, using in other ways, and not knowing how to integrate CT into the classroom.

In the pre-attitude questionnaire, $60 \%$ of the participants' statements reflected that for the integration of CT into the classroom, they need computers and technology. In contrast, for the post-attitude questionnaire only $28 \%$ of them supported that trend. PT 14 stated that, "As a teacher, we can give homework that are made by using technology and computer programs, also we can use Power Point Presentations, interactive whiteboard and e-books in the classroom."

For the promotion of problem-solving skills with the integration of the CT into their classrooms, the attitude of participants changed from $22 \%$ to $72 \%$. The last category of "Not know" decreased from $10 \%$ to $0 \%$, which shows that participants had a clear idea of integration of CT into the classroom. PT 15 wrote, "In biology lessons, we can give our students some projects in which they can use their problem-solving skills."
A: Promote problem solving skills/ critical thinking in the classroom
B: Utilizing computers and technology in the classroom
C: Other
D: Not know

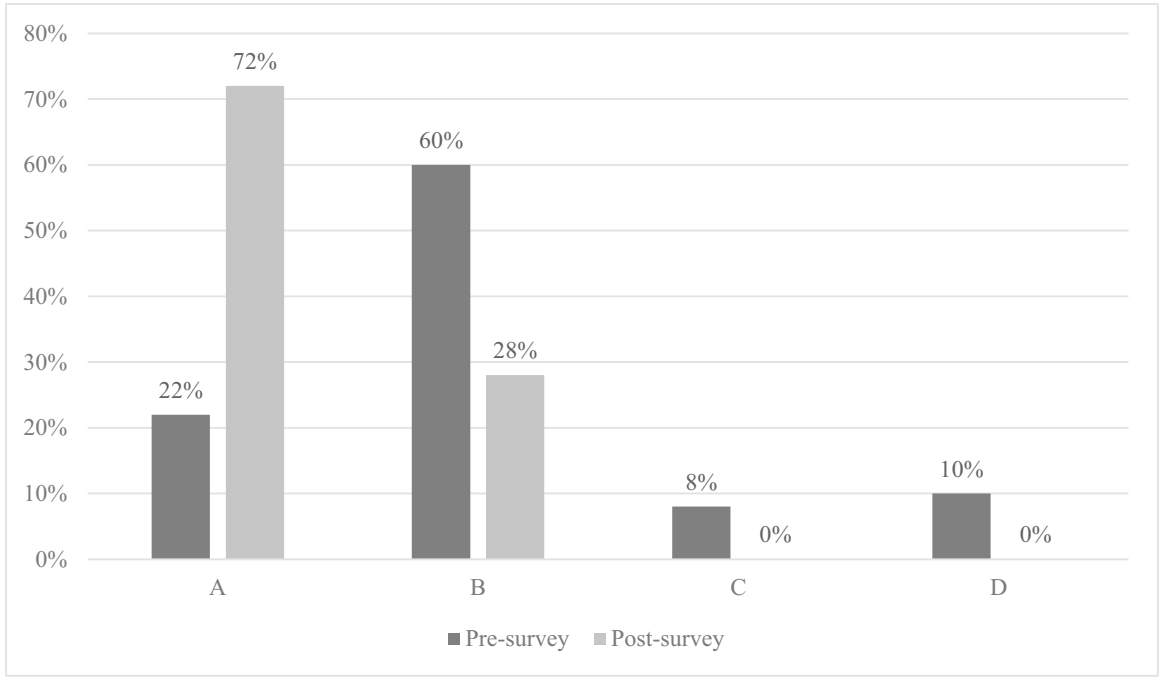

Fig. 5 Participants' view of integrating CT into the classroom according to the pre- and post-attitude questionnaire 
Pre-service teachers' lesson plans were also analysed by using the framework of ISTE for CT skills. The CT vocabulary (CTV) that they integrated into their lesson plans changed based on their subject area. All of the mathematics pre-service teachers $(n=14)$ included simulation and data collection into their lesson plans, second most chosen CTV was data collection $(n=12)$. The least chosen vocabulary by this group were parallelization and automation $(n=4)$. The figures were different for English language and literature pre-service teachers. The most integrated CTV into lesson plan was abstraction $(n=13)$, followed by data analysis $(n=11)$ and data collection $(n=9)$. The least preferred CTV into lesson plans by this group was automation $(n=2)$. Both Turkish language and literature and biology pre-service teachers' lesson plans mostly include data collection and data analysis as CTV. Turkish language and literature group chose simulation as a third CTV whereas biology group chose problem decomposition. Automation was not included in lesson plans by both Turkish language and literature and biology teachers. When we look at the overall picture including all subject areas; data collection and data analysis were the most included CTV, whereas parallelization and automation were the least selected ones to be included in lesson plans. Pre-service teachers' lesson plan analysis was given in Table 2.

Related with the data provided above, to give an overview of pre-service teachers' promotion of CT in their lesson plan, the summary of the four of the WebQuest products that they developed as part of the CT module is shared below.

The first example comes from a biology pre-service teacher:

Ecology Project: I want my students to make a little ecosystem in a bottle, Jar, or a light bulb. As a beginning, we will discuss which elements are included in an ecosystem. Also, we will discuss abiotic and biotic factors which are affected by ecosystems (Abstraction). Then, I will introduce them to what terrarium is and show a sample from internet and real life (Simulation). Later, they will search on the internet how to make an ecosystem and how to organize them in detail (Data collection). After that, I want them to decide their ecosystem whether will be aquatic or terrestrial. Also, which

Table 2 Data analysis of lesson plans

\begin{tabular}{llllll}
\hline CTV & $\begin{array}{l}\text { Mathematics } \\
(n=14)\end{array}$ & $\begin{array}{l}\text { English } \\
(n=13)\end{array}$ & $\begin{array}{l}\text { Turkish } \\
(n=7)\end{array}$ & $\begin{array}{l}\text { Biology } \\
(\mathrm{n}=11)\end{array}$ & $\begin{array}{l}\text { Total } \\
(n=45)\end{array}$ \\
\hline Data collection & 12 & 9 & 7 & 13 & 41 \\
Data analysis & 7 & 11 & 4 & 9 & 31 \\
Data representation & 9 & 7 & - & 4 & 20 \\
Problem decomposition & 7 & 7 & - & 6 & 20 \\
Abstraction & 7 & 13 & - & 2 & 22 \\
Algorithms \& procedures & 11 & 6 & - & 2 & 19 \\
Automation & 4 & 2 & - & - & 6 \\
Simulation & 14 & 4 & 4 & 4 & 26 \\
Parallelization & 4 & 6 & - & - & 10 \\
\hline
\end{tabular}


type of plant they can put in their terrariums. If they want, they can put some small animals like insects or snails. They will make a list of which materials are required (Data analysis). Next lesson, they will bring needed materials to the classroom, and we will make it together. Then we will discuss how we can take care of our ecosystem. We can make it relate with the ecology lessons (Algorithms \& Procedure).

Here is another example from an English language and literature pre-service teacher:

Conducting a survey: I have formed this activity to develop speaking skills of students. It is a communicative task. Students assume that they are researchers conducting a survey about Internet using habits. Students have some survey questions. They have 15 minutes to survey with different members of the class (Data collection). Then students gather into groups of 3-4. They discuss their findings and generate a chart. They reach a conclusion as a group of researchers (Data analysis). Then students assume that they have attended a conference about Internet use, and they will make a presentation about their survey results. Each group presents its findings and conclusions to the rest of the class (Data representation).

The third example comes from a mathematics pre-service teacher:

Probability: The activity focuses on connecting probability with algebra and geometry. The activity begins with asking a question: If a piece of spaghetti is broken at two randomly chosen points, what is the probability that the three pieces, placed end-to-end, can form a triangle? There are three approaches to solve this problem: by approaching directly, by using a computer program or calculator simulation, by graphical analysis. In order to form a triangle, students find several numbers for the lengths of triangle by collecting data (Data collection). To get data randomly, students use random number table, calculator simulation or computer simulation (Data representation \& Simulation). In the first approach, students will try to form triangles with spaghetti sticks by using random number table (Abstraction). After finding probability by using three approaches, students will compare the results in order way most accurate way to find the probability of triangle construction.

And the last example comes from a Turkish language and literature pre-service teacher:

Book interpretation: Firstly, I choose The Mysterious Affair at Styles book that is written by Agatha Christie. Students do not read the last chapter. I want students to behave like detectives and find who the murderer is by creating a diagram with profile cards of characters and completing a series of encryption activities based on the book. Students will input data about the suspects from profile cards based on the book and they will try to find the murderer (Data collection). They discuss their findings with other students. Students create a spreadsheet to simulate the events and their relationships with each character to find murderer (Simulation). 
As these examples claim, after the CT module, the participating student teachers developed insights into the ways CT can be integrated into their own disciplines. With the help of this activity, the module achieved its goals to promote pre-service teachers' computational thinking skills such as:

formulating problems in a way that helps them to use some tools to help solve them, organizing and analysing data, using models and simulations for representing the data, following ordered steps for algorithmic thinking, generalizing, and transferring this problem-solving process to a wide variety of problems. (Barr et al., 2011, p. 21)

Additionally, the pre-service teachers successfully used abstraction, decomposition, logical thinking, data analysis, algorithmic thinking, and debugging; skills that are required for computational thinking. It was not only their perceptions that changed according to the integration of CT into other disciplines, but they also followed what skills that were aimed for.

\section{Discussion}

According to Barr and Stephenson (2011), integration of CT in any curricula should include "demystifying terminology about computational thinking, give clear examples of ways it applies to and can be integrated into a range of curricular areas" (p. 53). In the present study, the results from the pre- and post-attitude questionnaires suggest that the CT module helped increase pre-service teachers' awareness of CT. Student teachers of different disciplines realized that computing and CT are more than using computers and technology but relate to the process of problem solving within their subject areas. In other words, their idea of using technology for pedagogical purposes extended beyond teachers' being consumers of technology to developing a sense of agency as teachers. This finding concurs with the previous studies on computational thinking suggesting that computational thinking through abstraction is a means for problem solving with the development of new perspectives and innovative solutions (Hemmendinger, 2010; Ioannidou et al., 2011).

The results also indicated that after participating in the CT module, pre-service teachers developed a better understanding of how to integrate CT into their teaching by not just using computers, but also through promoting problem solving and critical thinking skills such as abstraction and simulation in their lessons. Similar to Hambrusch et al.'s (2009) introductory course on CT, the module designed in this study was based on a problem-solving approach that introduced CT principles, concepts and issues by using a language that is familiar to the students. The module also encouraged students to integrate CT principles in their classes by demonstrating the contexts in which they might apply the CT principles while teaching. Hence, the results of this study confirm that these principles enable educators to establish a connection between computational thinking and disciplines other than science (Selby, 2015; Yadav et al., 2017). This finding is important as one of the challenges faced in applying CT to other disciplines results from the complicated nature of the definitions of CT especially to non-computer scientists (Cooper et al., 2010; Yeh et al., 
2011). Therefore, the principles applied in this study to teach the core concepts of CT and its integration into secondary classrooms proved to be useful for pre-service teachers who were going to teach Turkish, English, mathematics, and biology.

Last but not least, after the CT module, the student teachers in various disciplines agreed that computational thinking can and should be integrated into classroom education in other disciplines. This finding confirms that CT, due to its emphasis on problem solving and the role of computers in teaching and learning processes, extends beyond analytical and critical thinking that is required for computer scientists, to the fields of mathematics and science education as well as other subject areas such as language teaching (Cooper et al., 2010). As Wing (2006) stated, "To reading, writing, and arithmetic, we should add computational thinking to every child's analytic ability" (p. 33). In that sense, it is the teachers' responsibility regardless of their disciplines to integrate CT skills into their classes and provide opportunities for learners to develop these cognitive skills (Barr et al., 2011; Bundy, 2007; Mishra et al., 2013).

\section{Conclusion}

Overall, the results of this study suggested the many ways pre-service teachers in different disciplines integrated CT into their classes. The comments of the pre-service teachers in regard to the role of CT in their academic and social lives confirm that CT is one the twenty-first century literacy skills as the demands of daily and professional lives are expanding in scope and complexity. As a result, in order to prepare the students for these challenges, CT should be integrated into the curriculum of any teacher education program so that prospective teachers can effectively integrate CT-related skills in their classes.

This study supports previous research emphasizing the importance of exploring learners' attitudes towards CT. Yet, in order to be able to effectively integrate the CT principles into other disciplines, more descriptive studies are needed (Yadav et al., 2011; Yeh et al., 2011). Therefore, further research should be conducted on the possible strategies to teach the core concepts of CT, the various problems learners in other disciplines face in applying the principles of CT as well as the possible solutions to address those challenges.

\section{References}

Barr, V., \& Stephenson, C. (2011). Bringing computational thinking to K-12: What is involved and what is the role of the computer science education community? ACM Inroads, 2(1), 48-54. https://doi.org/10. $1145 / 1929887.1929905$.

Barr, D., Harrison, J., \& Conery, L. (2011). Computational thinking: A digital age. Learning \& Leading with Technology, 38(6), 20-23. https://eric.ed.gov/?id=EJ918910.

Bers, M. U., Flannery, L., Kazakoff, E. R., \& Sullivan, A. (2014). Computational thinking and tinkering: Exploration of an early childhood robotics curriculum. Computers \& Education, 72, 145-157. https:// doi.org/10.1016/j.compedu.2013.10.020.

Blikstein, P., \& Wilensky, U. (2009). An atom is known by the company it keeps a constructionist learning environment for materials science using agent-based Modelling. International Journal of Computers for Mathematical Learning, 14, 81-119. https://doi.org/10.1007/s10758-009-9148-8.

Bundy, A. (2007). Computational thinking is pervasive. Journal of Scientific and Practical Computing, 1, 67-69. https://www.inf.ed.ac.uk/publications/online/1245.pdf.

Cooper, S., Perez, L. C., \& Rainey, D. (2010). K-12 computational learning. Communications of the ACM, 53(11), 27-29. https://doi.org/10.1145/1839676.1839686. 
Corbin, J., \& Strauss, A. (2008). Basics of qualitative research: Techniques and procedures for developing grounded theory (3rd ed.). Sage.

Grover, S., \& Pea, R. (2013). Computational thinking in K-12: A review of the state of the field. Educational Researcher, 42(1), 38-43. https://doi.org/10.3102/0013189X12463051.

Hambrusch, S., Hoffmann, C., Korb, J. T., Haugan, M., \& Hosking, A. L. (2009). A multidisciplinary approach towards computational thinking for science majors. ACM SIGCSE Bulletin, 183-187. https:// doi.org/10.1145/1539024.1508931.

Hemmendinger, D. (2010). A please for modesty. ACM Inroads, 1(2), 4-7. https://doi.org/10.1145/1805724. 1805725.

Ioannidou, A., Bennett, V., Repenning, A., Koh, K. H., \& Basawapatna, A. (2011). Computational Thinking Patterns [Paper presentation]. Annual Meeting of the American Educational Research Association (AERA) in the Division C - Learning and Instruction/Section 7: Technology Research Symposium "Merging Human Creativity and the Power of Technology: Computational Thinking in the K-12 Classroom", Colorado. https://files.eric.ed.gov/fulltext/ED520742.pdf.

ISTE. (2011). Computational thinking: Teacher resources. Retrieved from https://www.iste.org/explore/artic leDetail ?articleid $=152 \&$ category $=$ Solutions \&article $=$ Computational-thinking-for-all.

Kramer, J. (2007). Is abstraction the key to computing? Communications of the ACM, 50(4), 36-42. https:// doi.org/10.1145/1232743.1232745.

Lam, T. C. M., \& Bengo, P. (2003). A comparison of three retrospective self-reporting methods of measuring change in instructional practice. American Journal of Evaluation, 24(1), 65-80. https://doi.org/10.1177/ 109821400302400106.

Lye, S. Y., \& Koh, J. H. L. (2014). Review on teaching and learning of computational thinking through programming: What is next for K-12? Computers in Human Behavior, 41, 51-61. https://doi.org/10.1016/j. chb.2014.09.012.

Miles, M. B., \& Huberman, B. M. (1994). Qualitative data analysis: A methods sourcebook (2nd ed.). Sage.

Mishra, P., Yadav, A., \& the Deep-Play Research Group. (2013). Of art and algorithms: Rethinking technology and creativity in the $21^{\text {st }}$ century. TechTrends, 57(3), 10-16. https://www.punyamishra.com/wpcontent/uploads/2013/03/Mishra-Yadav.pdf.

Nunnally, J. C. (1978). Psychometric theory (2nd ed.). McGraw-Hill.

Selby, C. C. (2015). Relationships: Computational thinking, pedagogy of programming, and bloom's taxonomy. In Proceedings of the workshop in primary and secondary computing education on ZZZ (pp. 80-87). ACM.

Sengupta, P., Kinnebrew, J. S., Basu, S., Biswas, G., \& Clark, D. (2013). Integrating computational thinking with K-12 science education using agent-based computation: A theoretical framework. Education and Information Technologies, 18, 351-380. https://doi.org/10.1007/s10639-012-9240-x.

Wing, J. M. (2006). Computational thinking. Communications of the ACM, 49(3), 33-35. https://doi.org/10. 1145/1118178.1118215.

Wing, J. M. (2008). Computational thinking and thinking about computing. Philosophical Transactions of the Royal Society, 366, 3717-3725. https://doi.org/10.1098/rsta.2008.0118.

Yadav, A., Zhou, N., Mayfield, C., Hambrusch, S. \& Korb, J. T. (2011). Introducing computational thinking in education courses. In Proceedings of the 42nd ACM Special Interest Group on Computer Science Education, 465-470, Dallas. https://cs4edu.cs.purdue.edu/_media/sigcse11-final.pdf.

Yadav, A., Hong, H., \& Stephenson, C. (2016). Computational thinking for all: Pedagogical approaches to embedding $21^{\text {st }}$ century problem solving in K-12 classrooms. TechTrends, 60, 565-568. https://doi.org/ 10.1007/s11528-016-0087-7.

Yadav, A., Gretter, S., Good, J., \& McLean, T. (2017). Computational thinking in teacher education. In P. J. Rich \& C. B. Hodges (Eds.), Emerging research, practice, and policy on computational thinking (pp. 205-220). Springer.

Yeh, K., Xie, Y., \& Ke, F. (2011). Teaching computational thinking to non-computing majors using spreadsheet functions. In Proceedings of the 41st ASEE/IEEE Frontiers in Education Conference. https://doi. org/10.1109/FIE.2011.6142980.

Yin, R. K. (2003). Case study research: Design and methods (3rd ed.). Sage.

Publisher's note Springer Nature remains neutral with regard to jurisdictional claims in published maps and institutional affiliations. 